\title{
Representações sociais sobre um Colégio de Aplicação: um estudo com os professores
}

\author{
Social representations about a Colégio \\ de Aplicação: a study with teachers
}

\section{Lísia Regina Ferreira Michels ${ }^{[a]}$, Maria Helena Villares Cordeiro $^{[\mathrm{b}]}$, Paula Correa Tavares ${ }^{[c]}$}

[a] Doutora em Educação - Psicologia da Educação pela Pontifícia Universidade Católica de São Paulo (PUC-SP), docente da Universidade do Vale do Itajaí (Univali), Itajaí, SC - Brasil, e-mail: lisia@univali.br

${ }^{[b]}$ Ph.D em Psicologia - University of London, docente da Universidade Federal da Fronteira Sul (UFFS), Chapecó - Brasil, e-mail: mhcordeiro@hotmail.com

[c] Psicóloga, Graduada pela Universidade do Vale do Itajaí (Univali), Itajaí, SC - Brasil.

\section{Resumo}

Esta pesquisa objetivou caracterizar as representações sociais, sobre a instituição, dos professores que atuam em um Colégio de Aplicação da região Sul do Brasil. A existência de diferentes representações sociais de professores pode afetar as relações entre os professores dos diferentes níveis de ensino e, consequentemente, o seu desenvolvimento profissional. Neste estudo foi adotada uma abordagem plurimetodológica, organizada em duas etapas distintas. Na primeira etapa, foi aplicado um questionário a 51 professores do colégio. Para a segunda etapa foram entrevistados três professores de cada nível 
de ensino, escolhidos aleatoriamente. A entrevista foi iniciada por meio da técnica de procedimento de classificações múltiplas e foi gravada e transcrita para análise qualitativa das falas. A partir da análise das falas dos professores, foi possível confirmar as representações sociais destes sobre o colégio. Emergiram três categorias da representação social: a primeira categoria corresponde aos elementos necessários à aprendizagem dos alunos. A segunda categoria refere-se aos elementos relacionados ao que seria um ideal de profissionalismo em uma dimensão institucional. A terceira categoria refere-se aos atributos pessoais de qualidade do professor.

Palavras-chave: Representações sociais. Educação. Colégio de Aplicação.

\section{Abstract}

This research aimed at characterizing the social representations of teachers working in a Colégio de Aplicação (a school maintained by a university) in Southern Brazil, we focused on the institution where they work at. The existence of different social representations of teachers can affect the relationships between teachers at different educational levels and, consequently, their professional development. For this study it was adopted a pluri-methodological approach, organized into two distinct stages. For the first stage, a questionnaire was administered to 51 school teachers. For the second stage three teachers from each school level were chosen randomly and interviewed. The interview was initiated by the technique procedure of multiple classifications; the statements were recorded and transcribed for qualitative analysis. From the speech of the teachers, it was possible to confirm the social representations of them on the school, as a result of it; three categories of social representations were revealed: the first category corresponds to the necessary materials for the students learning. The second category refers to the related items to what would be an ideal of professionalism in an institutional dimension. The third category refers to personal attributes of teacher quality.

Keywords: Social representations. Education. Colégio de Aplicação. 


\section{Introdução}

A Teoria das Representações Sociais tem sua origem em Moscovici, em 1961, com sua obra La psychanalyse son image et son publique. Farr (1995) a considera uma continuação moderna do estudo das representações coletivas de Durkheim. O autor afirma que as representações coletivas eram mais apropriadas para estudar sociedades menos complexas, e as sociedades atuais são marcadas por seu pluralismo e por mudanças econômicas, políticas e culturais cada vez mais rápidas. Assim, poucas representações, hoje, podem ser consideradas realmente coletivas. Contudo, a Teoria das Representações Sociais mostra a influência das representações coletivas ao considerar o indivíduo um produto da sociedade. Segundo o mesmo autor, devemos estudá-las em ambos os contextos em que estão presentes: tanto no 'mundo' como na 'mente', e só vale a pena estudá-las se elas estiverem espalhadas dentro da cultura na qual o estudo é realizado.

As representações sociais (RS) têm como foco de estudo a relação entre o sujeito e o objeto, recuperando um sujeito que, por meio dessa relação e de sua atividade, constrói esse objeto-mundo e também é construído por ele. Estabelecendo uma síntese entre fenômenos que estão interligados, nos deparamos com as dimensões cognitiva, afetiva e social, presentes até mesmo na noção de representações sociais. A dimensão cognitiva está envolvida na medida em que as representações sociais envolvem a construção de saberes sociais; quando os sujeitos sociais tentam entender e dar sentido ao mundo, por meio de uma significação simbólica, eles o fazem com emoção, sentimento e paixão, envolvendo um ato afetivo; e a realidade social é a base tanto para a cognição como para os afetos que estão presentes nas representações sociais. Assim, as representações sociais são formadas quando as pessoas se encontram para discutir o cotidiano, ou quando elas estão expostas às instituições, aos meios de comunicação, aos mitos, e à herança histórico-cultural de suas sociedades (GUARESCHI; JOVCHELOVITCH, 1995).

Nessa perspectiva, Jodelet (2007) assinala que as representações sociais têm uma origem e um objetivo: elas se originam na experiência das 
pessoas e têm a função de orientação na conduta das pessoas no seu cotidiano. E, ainda, a representação social produz uma visão partilhada em um grupo social, tal visão é considerada uma evidência para os membros desse grupo e ajuda na leitura do mundo cotidiano. A autora compara tal tipo de conhecimento ao saber científico, diferenciando-os pela vulgarização científica, graças à atividade de aprendizagem que ela demanda.

Guareschi e Naujorks (2006) consideram que as representações sociais influenciam nossas práticas sociais por serem saberes do senso comum, ou seja, são construídas nas relações entre os indivíduos. Assim, elas são elaboradas no cotidiano, quando as pessoas conversam, analisam, criticam e pensam sobre diversos temas.

A proposta de Moscovici (2003) é considerar fenômeno o que antes era considerado um conceito. Para o autor, as representações são criadas por meio da comunicação e da cooperação das pessoas e dos grupos, logo não são geradas isoladamente pelas pessoas. Elas influenciam o comportamento de um indivíduo dentro de uma coletividade, e o pensamento coletivo penetra no pensamento individual. Ao estudarmos as representações sociais, estudamos o processo de conhecer e de compreender do indivíduo, em vez de seu comportamento, estudando-o enquanto ele pensa, pergunta e tenta responder.

Uma abordagem mais estrutural das representações sociais é desenvolvida por Jean-Claude Abric, em 1994, chamada de Teoria do Núcleo Central. A principal ideia dessa teoria é que todas as representações são estruturadas em volta de um núcleo central e elementos periféricos. Assim, o que diferencia uma representação de outra é sua organização estrutural (PAVARINO, 2004 apud KLEIN, 2006).

De acordo com o autor, o núcleo central apresenta maior estabilidade e resistência a mudanças e está relacionado com a memória coletiva, assim, ele atribui mais significação, consistência e permanência às representações sociais. Já os elementos periféricos são mais flexíveis, acessíveis e suscetíveis de adaptação e protegem o núcleo central. Essa organização estrutural permite uma compreensão das características contraditórias e complementares que possuem as representações sociais, da estabilidade e flexibilidade, e de consenso e diferença. 
Para Abric (2000 apud FERNANDES, 2004) os elementos periféricos constituem a essência do conteúdo da representação e são os responsáveis pelas representações mais individualizadas, com características próprias do indivíduo, e do contexto no qual ele está inserido. Já o núcleo central unifica e estabiliza a representação, pois ele une entre si seus elementos. $\mathrm{O}$ autor atenta para dois fatores fundamentais que devem ser levados em consideração em análises da prática social por meio das representações sociais: as condições sociais, históricas e materiais, em que as práticas sociais estão presentes, e o modo de apropriação pelos indivíduos ou grupos a que tais práticas estão relacionadas.

Villas Bôas (2004) concluiu que o estudo das RS tem um lugar importante na educação na medida em que pode contribuir na elaboração de novas práticas educativas, na sala de aula, e de novos entendimentos sobre sua realidade. Sousa (2002, p. 297) acrescenta que o conhecimento das representações sociais na educação possibilita transformações positivas, pois, a partir de tal conhecimento, pode-se analisar criticamente essas representações, saber seus fundamentos, os valores e crenças atribuídos por determinado grupo social, para então "construir uma nova visão de mundo, formar e promover a educação no sentido amplo e restrito do termo". Contudo, a autora afirma que transformar uma prática educativa, qualquer que seja, é uma trajetória longa, que exige uma atuação com o professor e a estrutura escolar, na busca da construção de novas relações.

Para Jodelet (2007), o campo da educação tem se utilizado muito da metodologia das representações sociais por esta oferecer muitas possibilidades na aproximação das diferentes significações produzidas no processo educativo. Significações essas presentes nos discursos dos agentes da educação, relacionados às suas posições sociais. Outra razão apontada pela autora é a influência exercida pelas representações nas concepções e avaliações da relação pedagógica e, consequentemente, o que a possibilita.

Gilly (2002) aponta como as representações sociais esclarecem o papel de grupos de significações sociais na educação, pois elas explicam como os fatores sociais influenciam o processo educativo e os resultados tdeste, favorecendo a articulação entre psicossociologia e sociologia da 
educação. Os estudos na educação contribuem para as questões mais gerais das representações sociais por pesquisarem sua construção e suas funções. No campo educativo, é possível ver como elas se constroem, evoluem e se transformam dentro de um grupo social, demonstrando assim o papel que essas construções têm na relação do sujeito com suas representações.

As representações sociais permitem aos indivíduos a garantia da preservação de seu equilíbrio e sua coerência, necessários para suas práticas e relações sociais. A autora anteriormente citada aponta que, dentro da escola, existem diferentes representações sociais, muitas vezes contraditórias, que variam de acordo com a posição em relação à escola. Tais contradições operam sob duas pressões, pelas ideologias, e por aquilo que é esperado do sistema escolar, como suas finalidades e suas condições. O sistema de representações sociais sintetiza de forma coerente esses dois lados, articulando essas contradições existentes entre a ideologia e a realidade, cumprindo, dessa forma, sua função de legitimar o sistema e justificar práticas.

Jodelet (2007) alerta para o fato de que se deve evitar a redução do campo educativo ao modelo das representações sociais e vice-versa; pois a educação não é apenas um objeto para coleta de dados ou aplicação de uma teoria, e sim um espaço que, em sua totalidade, oferece, para as representações, recursos que devem ser adaptados de acordo com as características de sua estruturação. Portanto, a Teoria das Representações Sociais, por ter seus conceitos e procedimentos próprios, não deve ser utilizada apenas na transferência para outros campos, o que confirma a necessidade de uma articulação entre os dois campos, entre suas problemáticas e suas perspectivas.

\section{A pesquisa}

\section{1a etapa}

Nesta etapa, serão apresentados os encaminhamentos adotados para conhecer o conteúdo das representações sociais sobre o Colégio de 
Aplicação e seus elementos constituintes. Participaram da primeira etapa 51 professores. Estes foram abordados no colégio individualmente, nos intervalos ou em horários em que não estavam na sala de aula, sem atividades com os alunos. No primeiro momento, foi explicado sobre o Termo de Consentimento Livre e Esclarecido, de acordo com Resolução 196/96 do Conselho Nacional de Saúde. Em seguida, foi solicitado que o professor falasse quatro palavras que viessem à mente, a partir do estímulo: Colégio de Aplicação.

\section{Análise dos dados}

Foram citadas 91 palavras diferentes pelos sujeitos, diante da expressão indutora "Colégio de Aplicação". Essas palavras foram processadas pelo programa EVOC (Tabela 1), que considera simultaneamente a frequência e a ordem das representações. Por intermédio do processamento realizado pelo programa, é possível organizar grupos de evocações, segundo sua saliência (obtida pela ordem de evocação) e seu grau de compartilhamento no grupo (obtido pela frequência com que foi evocado). A tabela formada possui quatro quadrantes: no primeiro, contém as palavras mais frequentes e que foram citadas mais rapidamente, o que significa que essas palavras pertencem ao núcleo central da representação. O segundo quadrante apresenta-se como um sistema intermediário, formado pelas palavras mais frequentes, mas que foram lembradas mais tardiamente, o que permite supor que essas palavras podem estar fortemente associadas às do núcleo central. O terceiro e o quarto quadrante representam o sistema periférico, formado pelas palavras menos frequentes, que foram citadas por apenas alguns sujeitos; dessa forma, elas podem auxiliar no conhecimento dos sentidos atribuídos pelos diferentes sujeitos ao objeto da representação. Esse sistema contém significados que nos ajudam a compreender a permanência da representação, assim como os que anunciam as possibilidades de transformá-la. 
Tabela 1 - Tabela com as 20 palavras mais citadas pelos professores

\begin{tabular}{|c|c|c|c|c|c|}
\hline \multicolumn{6}{|c|}{ Frequência >= 8} \\
\hline \multicolumn{3}{|c|}{ Ordem média $<=2,5$} & \multicolumn{3}{|c|}{ Ordem média $>=2,5$} \\
\hline & $\mathrm{F}$ & OM & & $\mathrm{F}$ & OM \\
\hline Compromisso & 10 & 1,50 & \multirow[t]{4}{*}{ Amizade } & \multirow[t]{4}{*}{9} & \multirow[t]{4}{*}{3,57} \\
\hline Educação & 10 & 2,20 & & & \\
\hline Qualidade & 11 & 2,18 & & & \\
\hline Responsabilidade & 8 & 2,37 & & & \\
\hline \multicolumn{6}{|c|}{ Frequência < 8} \\
\hline & $\mathrm{F}$ & OM & & $\mathrm{F}$ & OM \\
\hline Aprendizagem & 7 & 2,14 & Alegria & 5 & 3,00 \\
\hline Comprometimento & 6 & 1,50 & Conhecimento & 6 & 3,00 \\
\hline \multirow[t]{9}{*}{ Trabalho } & 6 & 2,33 & Dedicação & 5 & 3,60 \\
\hline & & & Profissionalismo & 5 & 3,20 \\
\hline & & & Universidade & 5 & 2,60 \\
\hline & & & Estudo & 4 & 2,00 \\
\hline & & & Satisfação & 4 & 1,75 \\
\hline & & & Alunos & 3 & 1,33 \\
\hline & & & Diversidade & 3 & 2,33 \\
\hline & & & Liberdade & 3 & 1,67 \\
\hline & & & Respeito & 3 & 3,00 \\
\hline
\end{tabular}

Fonte: Dados da pesquisa.

É importante salientar que somente dois professores da educação infantil relacionaram o Colégio de Aplicação à universidade. As evocações foram: aplicação, graduação, pesquisa e projetos. Isso pode estar relacionado ao fato de que o grupo de professoras da educação infantil participa, voluntariamente, de um programa de formação de professores que está vinculado ao Mestrado em Educação. 


\section{2a etapa}

Nesta etapa, serão apresentados os encaminhamentos utilizados para conhecer a estrutura da representação social sobre o Colégio de Aplicação, identificando como os elementos se organizam no campo da representação. Foram sorteados 12 professores, sendo três da educação infantil, três das séries iniciais, três do ensino fundamental e três do ensino médio. Foi utilizado o procedimento de classificações múltiplas (PCM), solicitando aos professores que categorizassem, em grupos, as 20 palavras mais lembradas na primeira etapa. Primeiramente, as oito palavras que se relacionavam com o $\mathrm{CAU}$, positivamente, que despertassem sentimentos agradáveis; em seguida, que fossem separadas oito que se relacionavam negativamente, despertando sentimentos negativos. $\mathrm{Na}$ sequência, foi solicitado que, das oito palavras positivas, o professor escolhesse as mais importantes, que se relacionavam ao CAU. Em seguida, foi solicitado ao professor que realizasse o mesmo procedimento com as palavras negativas: das oito palavras, selecionasse as quatro que lhe despertassem mais sentimentos negativos.

Durante a categorização das palavras, alguns professores justificaram suas escolhas e outros não. Contudo, todas as entrevistas foram gravadas e transcritas.

\section{Análise dos dados}

No início da coleta, a maioria dos professores apresentou dificuldade no momento de separar as palavras que se relacionavam com o CAU negativamente. Os professores relataram que nenhuma das palavras apresentadas poderia ser vista como negativa, ou até mesmo que não viam aspectos negativos no colégio. Mesmo após ser sugerido que poderia ser algo que estivesse faltando no colégio, alguns professores disseram que essa era uma tarefa muito difícil. No entanto, a partir do momento em que separavam a primeira palavra, e pensavam sobre ela, novas ideias 
iam surgindo e dessa palavra surgia uma relação com outra, e assim por diante, até chegar à oitava palavra.

Os agrupamentos formados pelos professores foram submetidos a uma análise multidimensional, utilizando-se a Multidimensional Scalogram Analysis (MSA). Cada palavra categorizada é representada por um ponto, de forma que as palavras que foram colocadas com mais frequência na mesma categoria aparecem mais próximas no diagrama (Figura 1).

O diagrama produzido foi dividido em três regiões. Na região à esquerda, estão os elementos ideais para os professores, em uma dimensão institucional. Na perspectiva dos professores, a universidade deveria

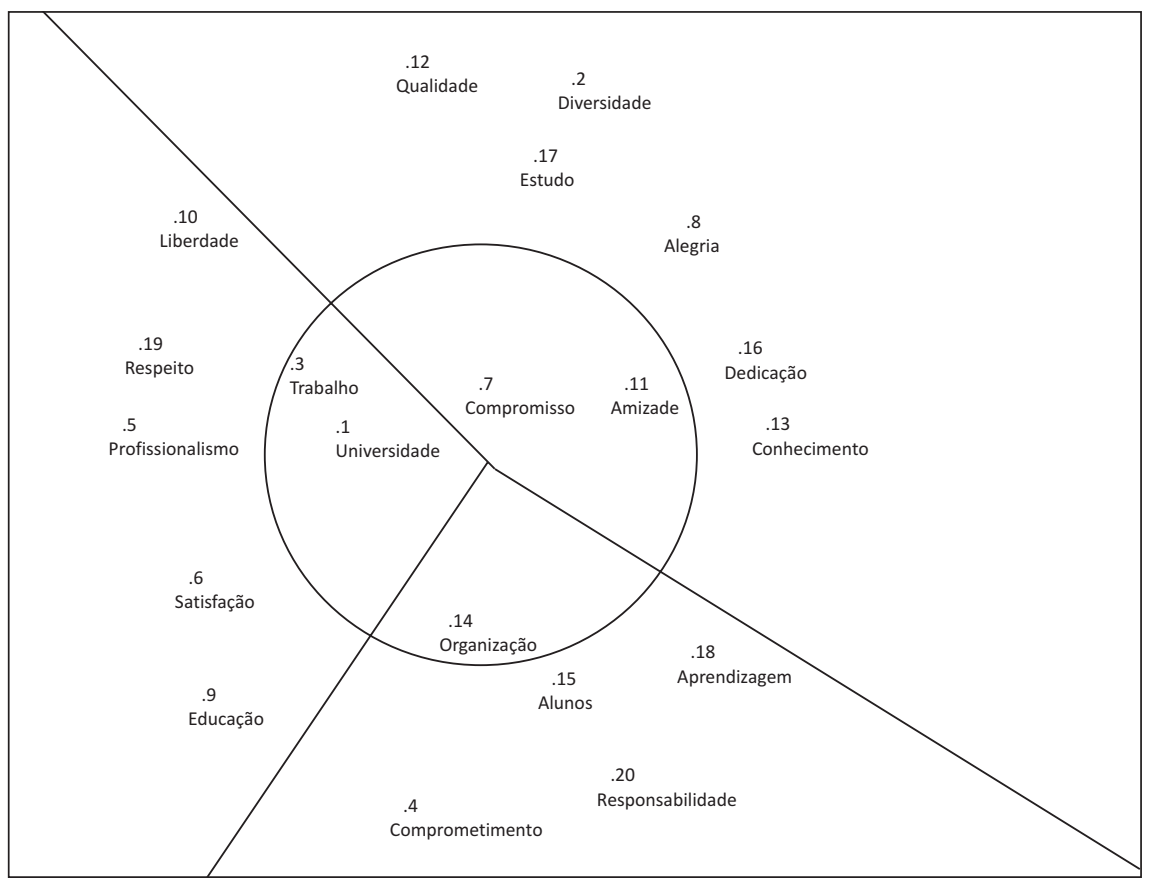

Figura 1 - Diagrama produzido pelo programa MSA com as categorizações dos professores

Fonte: Dados da pesquisa. 
proporcionar: satisfação, liberdade e respeito; e os profissionais que nela trabalham devem ter profissionalismo e educação. Donaduzzi (2003) afirma que as representações sociais de professores unem as ideias que propagam, tanto na sociedade quanto no grupo ao qual pertencem, e se reconstroem por meio de suas experiências, de sua história e suas relações sociais, incluindo a formação recebida.

Na região superior à direita, as evocações estão relacionadas aos atributos pessoais de qualidade do professor, às qualidades que são esperadas dele: qualidade, diversidade, estudo, alegria, dedicação, compromisso, amizade e conhecimento. Nessa categoria, foram elencados tanto os atributos considerados já existentes nos professores do colégio como os que estão faltando. Ao se referir aos atributos que estão faltando, os professores avaliaram somente o que faltava aos demais docentes. Os atributos de qualidade do professor remetem ao bom docente. Teves e Rangel (1999, p. 48), ao discutir as dimensões da representação do bom educador, relacionaram as dimensões do processo ensino-aprendizagem ao estudo da didática, notando-se "os apelos à qualidade do ensino que, por muitas formas e muitos vínculos, associa-se à qualidade de vida”.

Na região inferior à direita, há como elementos centrais o aluno e a aprendizagem deste, e também os elementos necessários a essa aprendizagem: organização, responsabilidade e comprometimento.

\section{3a etapa}

Nesta etapa, serão apresentados os métodos utilizados para compreender a dinâmica da representação social, conhecendo como se geram, se transformam e ou se reproduzem os diferentes significados atribuídos aos elementos da representação. Para responder à questão referente à dinâmica da representação, foram utilizadas as falas dos professores que justificaram e explicaram suas categorizações no PCM. Durante as categorizações, dez professores justificaram suas escolhas e dois professores não justificaram. 
No segundo momento dessa etapa da coleta, foram solicitadas as evocações relacionadas aos aspectos negativos do colégio. Dentre os 12 professores entrevistados, quatro apontaram os aspectos negativos; sete consideraram que essa era uma tarefa muito difícil, justificando que não havia palavras que pudessem ser colocadas como negativas; e somente um dos professores manifestou que, naquele momento, não havia aspectos negativos no colégio.

\section{Análise e discussão das justificativas produzidas no PCM}

A partir da análise das falas dos professores, foi possível confirmar as representações sociais destes sobre o colégio. Emergiram três categorias da representação social: a primeira categoria corresponde aos elementos necessários à aprendizagem dos alunos. A segunda categoria refere-se aos elementos relacionados ao que seria um ideal de profissionalismo, em uma dimensão institucional. A terceira categoria refere-se aos atributos pessoais de qualidade do professor.

Sousa (2002) considera que as pesquisas das representações sociais de professores permitem conhecer as ideologias do contexto educacional, no qual os sentidos que tais professores dão à sua conduta estão sendo construídos, pois as representações revelam a visão funcional que um grupo tem do mundo. A autora analisou algumas pesquisas na área, e as categorizou de acordo com suas vertentes. Nas pesquisas que têm como foco a ideologia das representações, a principal questão era o papel que as representações de professores têm na construção das formas de pensar dos alunos e a influência que exercem na orientação das comunicações de sua conduta. Essa categoria também busca identificar como os professores se situam simbolicamente em seus grupos sociais.

Moscovici (2003) considera que o objetivo final das representações sociais é tornar algo não familiar em familiar, e por essa não ser uma tarefa fácil são necessários dois processos baseados na memória e em conclusões passadas. Tais processos transformam palavras, ideias e 
pessoas estranhas em usuais, por meio de sua transferência para nossa esfera particular, assim, nós comparamos com outros já existentes e interpretamos - esse processo é denominado ancoragem. Posteriormente, reproduzindo-os ao concreto, aquilo que podemos ver e tocar - e dessa forma controlar -, processo chamado de objetivação.

$\mathrm{Na}$ ancoragem, transformamos aquilo que nos é estranho e perturbador ao nosso conjunto particular de categorias, classificando-o na categoria que nos parece mais apropriada, estabelecendo uma relação positiva, ou negativa, e assim damos um nome familiar, que nos seja mais usual, próximo e atual. "Ancoramos o desconhecido em representações já existentes". O segundo processo, a objetivação, consiste na transformação de algo invisível em visível, abstrato em concreto (SPINK, 1993).

$\mathrm{Na}$ categoria relacionada à aprendizagem dos alunos, a representação dos professores está ancorada na responsabilidade e na organização dos estudantes. Os alunos estão muito presentes na representação dos professores, como pode ser percebido nas seguintes falas:

fazendo o aluno feliz tem ensino de qualidade (Sujeito 8).

Organização, tem sempre aquele aluno que não trás o material ou que deixa de cumprir alguma coisa, porque não marcou, não é organizado, não sabe usar sua agenda (Sujeito 37).

Muitos alunos também confundem esse pensamento, por ser tão livre, tão aberto, com tanta autonomia, às vezes esquecem da questão da responsabilidade (Sujeito 48).

A representação dos professores pareceu, ainda, estar ancorada na falta de comprometimento dos demais professores com o colégio. Isso pode ser analisado nas seguintes falas:

comprometimento: falta de algumas pessoas, não minha, mas de algumas pessoas, aí isso gera um desconforto meu e da minha equipe, porque não há esse comprometimento (Sujeito 2). 
$\mathrm{Na}$ categoria trabalho, os professores se expressaram sobre o que seria o ideal de profissionalismo, em uma dimensão institucional, e o que seria ideal na relação deles com a universidade. Para eles, a universidade deveria proporcionar liberdade, satisfação e respeito. E o trabalho deles, em função da educação, deveria ter mais profissionalismo. A liberdade apareceu de forma dicotômica na representação dos professores, porque eles sentem que têm liberdade, mas, na prática, ela não é utilizada de forma adequada, como pode ser analisado nas falas dos participantes:

acho que a gente tem autonomia pra ter uma liberdade, até porque somos profissionais, tem que ter essa liberdade, lógico que moderada, até onde começa a [liberdade] do outro (Sujeito 8).

A liberdade é percebida como algo individual e não como uma possibilidade de participação coletiva nas decisões:

eu posso pegar a liberdade pra falar de outra coisa, no sentido de [que], às vezes, as pessoas usam essa palavra de forma errada aqui. Não que elas sintam que possam fazer o que quiserem, não é isso, ao contrário: de achar que não podem fazer nada, que tudo é um problema. Então, pra algumas coisas elas sentem que, por já estarem aqui há tempo, que são amigas, que podem fazer as coisas, mas na ação profissional mesmo se sentem amedrontadas com isso. Acho que tem uma falta de entendimento dessa palavra (Sujeito 1).

Os professores assinalam que existe liberdade no CAU, mas falta autonomia:

não sei se é porque aqui a gente tem uma sistemática de liberdade também muito grande, talvez essa dedicação, e essa liberdade, às vezes, é confundida e não são tão dedicados (Sujeito 48).

Na representação dos professores, a satisfação aparece como muito importante para o processo de aprendizagem, mas é percebida uma falta de satisfação, tanto em professores quanto em alunos. 
Eu vejo a educação aqui dentro. Se o professor está ensinando com satisfação, com certeza a educação está aqui, o aluno vai aprender com qualidade, então eu vejo a educação como importante, mas também vejo que, para que ela aconteça, tem a satisfação (Sujeito 8).

O respeito apareceu muito ligado à educação; e o trabalho, ao profissionalismo. A representação social dos professores mostra que existe falta de respeito dos alunos em relação ao professor.

Respeito. Às vezes misturam, não são tão profissionais, misturam, relacionamento lá fora (Sujeito 2).

Temos muito grupo de estudos, e diante disso tudo tem o profissionalismo (Sujeito 2).

Nas justificativas dos professores, estiveram muito presentes explicações sobre a categorização da universidade, colocada por seis professores como um aspecto negativo do CAU e, por outros seis professores, como aspecto positivo. Destacam-se as vantagens e desvantagens da inserção do colégio na universidade, como pode ser analisado nas falas a seguir:

eu acho muito fundamental a universidade, a gente estar inserido na universidade, acho bem importante, mas, às vezes, está se deixando algumas coisas, que eu acho necessário, por conta dela. Ela entra como algo positivo, mas também é uma faca de dois gumes, digamos assim. Mas eu vejo ela como algo muito importante... o colégio estar inserido numa universidade... nesse sentido acho que ela atrapalha um pouco (Sujeito 8).

Universidade, eu acho que entra até nas coisas boas, porque pra mim já entra em diversidade, que é a minha visão, mas, às vezes, eu também posso colocar no negativo, no sentido de que o CAU às vezes é engolido pela universidade, então pode ser um ponto negativo; mas também é positivo pelo fato de estar dentro da universidade, a gente ganha muito com isso também (Sujeito 1).

$\mathrm{Na}$ categoria constituída por atributos pessoais de qualidade do professor, a diversidade emerge no discurso dos professores, como um ponto 
positivo do colégio, ela é relatada no sentido da diversidade de alunos, referindo-se à política de inclusão de alunos com deficiência, e aparece também como uma diversidade de pontos de vista, de opiniões diferentes:

a diversidade jamais será desagradável, ela precisa existir para acontecer o aprendizado (Sujeito 8).

Diversidade, isso aqui é muito grande dentro do espaço, eu acho que é uma das características muito forte do Colégio de Aplicação, é a diversidade, diversidade de ideias, conflitos de ideias, entre os professores mesmo, sabe assim, eu percebo assim, o pessoal colocando seu ponto de vista, discutindo com alunos, tudo é muito discutido, tudo muito explicado, tudo muito trabalhado, eu vejo essa questão (Sujeito 11).

O estudo e o conhecimento surgiram como um atributo importante, que deve ser buscado pelos professores e alunos, mas que está faltando no colégio.

A vontade de aprender e de adquirir o conhecimento, nem todos do grupo do CAU pensam assim, tem uns que já estão um pouco acomodados, e acho que isso soa negativo para o CAU, deixo bem claro, não é o grupo, alguns membros do grupo, sempre tem (Sujeito 8).

É ressaltada a necessidade de maior dedicação, principalmente por parte dos professores. De acordo com o discurso, a dedicação é um atributo pessoal importante na profissão: tem alguns profissionais que de repente precisam um pouco mais disso, dedicação (Sujeito 8).

Em relação à amizade, surgiram pontos de vista diferentes, porque foi relatado que a amizade é essencial ao grupo, ao colégio, mas também é algo secundário e que às vezes até atrapalha.

A amizade: existe um grupo de professores que existe amizade, mas não é na totalidade que a gente consegue, e isso é um ponto positivo pra coisa fluir. Se existe um amigo no grupo, que não se considere amigo, ou que esteja ali, não pra somar, mas pra dividir, aí a coisa já não flui, e isso existe no grupo 
também, não diria, cem por cento, mas existe em alguns grupos, e isso atrapalha o CAU (Sujeito 8).

A qualidade surge como um aspecto presente no colégio, mas que deve buscar-se cada vez mais. Há uma relação das evocações 'qualidade' e 'compromisso', no sentido de existir um compromisso com a qualidade:

o compromisso com a qualidade, não estou colocando eu, a falta de compromisso meu, eu tenho, a gente vê como outras pessoas que não têm esse compromisso, aí desvalorizam (Sujeito 2).

A alegria é colocada como algo que deve existir no colégio, para que o aprendizado aconteça melhor, mas que em alguns momentos ela falta. Planejar com alegria, aí as estratégias ficam mais interessantes e assim o aprendizado acontece de uma forma melhor (Sujeito 8).

\section{Considerações finais}

Para analisar as representações sociais de professores é necessário compreender o contexto sociopolítico educacional no qual estes estão inseridos. A análise dessas representações permite o desenvolvimento de melhores práticas educativas e possibilita o aperfeiçoamento da formação de professores e melhorias na escola. O estudo das representações sociais de professores possibilita a compreensão do pensamento daqueles que ajudam a construir a escola; e o pensamento construído pelos professores, com base em suas experiências e formas de pensamento, é o processo de construção da realidade escolar (SOUSA, 2002).

Diante da análise das entrevistas com os sujeitos da pesquisa, foi possível concluir que a representação social dos professores sobre o CAU está ancorada em três categorias inter-relacionadas. No discurso dos professores surgiu uma ambiguidade na aprendizagem dos alunos, e essa aprendizagem fica localizada entre as qualidades necessárias ao professor 
e a organização da instituição, mais especificamente da universidade. O aluno surge entre essas duas dimensões, sofrendo influência de ambas, e sua aprendizagem é condicionada por essa influência.

Diante das análises empreendidas sobre as falas dos professores, as representações sociais indicam que a falta de organização do CAU está relacionada à sua inserção na universidade. Outro aspecto da RS dos professores revela que falta uma identidade própria ao colégio, que mantém com a universidade apenas uma relação burocrática e verticalizada. Dessa forma, existe uma inadequação nessa inserção, pois a estrutura da universidade, que é uma estrutura voltada ao ensino de graduação e pós-graduação, parece não estar compatível à estrutura necessária para um colégio destinado aos níveis de educação infantil, ensino fundamental e ensino médio. Assim, o CAU torna-se mais um conjunto de professores, sem uma identidade profissional definida. No âmbito da identidade docente, Nóvoa (1995) apresenta uma importante contribuição na área da educação. Na perspectiva assumida pelo autor, a identidade profissional está relacionada a três aspectos: o desenvolvimento pessoal, que está ligado aos processos de produção da vida do professor; o desenvolvimento profissional, que está relacionado à profissionalização docente; e o desenvolvimento institucional que está relacionado aos investimentos da instituição para a realização dos seus objetivos educacionais.

Diante das reflexões empreendidas, este estudo é relevante na área da educação e, em especial, no estudo das representações sociais de professores, ao analisar as ancoragens dos professores e suas implicações no processo educacional.

\section{Referências}

DONADUZZI, A. Explico uma vez, eles fazem: a representação social do bom aluno entre as professoras do início do ensino fundamental. 2003. $86 \mathrm{f}$. Dissertação (Mestrado em Educação) - Programa de Pós-Graduação Stricto Sensu em Educação, Universidade do Vale do Itajaí, Itajaí, 2003. 
FARR, R. M. Representações sociais: a teoria e sua história. In: GUARESCHI, P. A.; JOVCHELOVITCH, S. (Org.). Textos em representações sociais. 4. ed. Petrópolis: Vozes, 1995. p. 31-59.

FERNANDES, M. Z. Representação social do bom professor da educação infantil. 2004. 138 f. Dissertação (Mestrado em Educação) - Centro de Ciências Humanas e da Comunicação, Universidade do Vale do Itajaí, Itajaí, 2004.

GILLY, M. Representações sociais no campo educativo. Educar, Curitiba, n. 19, p. 231-252, 2002. Disponível em: <http://calvados.c3sl.ufpr.br/ojs2/index.php/ educar/article/viewFile/2092/1744>. Acesso em: 20 nov. 2009.

GUARESCHI, P. A.; JOVCHELOVITCH, S. (Org.). Textos em representações sociais. 4. ed. Petrópolis: Vozes, 1995.

GUARESCHI, T.; NAUJORKS, M. I. As representações sociais de professores acerca da aprendizagem de alunos com distúrbios globais do desenvolvimento. REUNIÃO ANUAL DA ANPED, 29., 2006, Caxambu. Anais... Caxambu: ANPED, 2006. Disponível em: <http://www.anped.org.br/reunioes/29ra/trabalhos/trabalho/GT15-2192--Int.pdf >. Acesso em: 30 jun. 2007.

JODELET, D. Contribuições das representações sociais para a análise das relações entre educação e trabalho. In: PARDAL, L. et al. (Org.). Educação e trabalho: representações, competências e trajectórias. Aveiro: Universidade de Aveiro, 2007. p. 11-25.

KLEIN, J. A. A representação social sobre a matemática de professoras da educação infantil e séries iniciais do ensino fundamental de escolas da rede municipal de Itajaí-SC. 2006. 105 f. Dissertação (Mestrado em Educação) - Centro de Ciências Humanas e da Comunicação, Universidade do Vale do Itajaí, Itajaí, 2006.

MOSCOVICI, S. Representações sociais: investigações em psicologia social. Petrópolis: Vozes, 2003.

NÓVOA, A. (Coord.). Os professores e a sua formação. 2. ed. Lisboa: Dom Quixote, 1995. 
SOUSA, C. P. Estudos de representações sociais em educação. Psicologia da Educação, São Paulo, n. 14/15, p. 285-323, 2002.

SPINK, M. J. P. O conceito de representação social na abordagem psicossocial. Caderno Saúde Pública, Rio de Janeiro, v. 9, n. 3, 1993. Disponível em: <http://www.scielo.br/scielo.php?script=sci_arttext\&pid=S0102-311X1993000 300017\&lng=pt\&nrm=iso $>$. Acesso em: 30 jun 2007.

TEVES, N.; RANGEL, M. Representação social e educação. Campinas: Papirus, 1999.

VILLAS BÔAS, L. P. S. Teoria das representações sociais e o conceito de emoção: diálogos possíveis entre Serge Moscovici e Humberto Maturana. Psicologia e Educação, v. 19, p. 143-166, 2004. Disponível em: <http://pepsic.bvs-psi.org.br/ scielo.php?script=sci_arttext\&pid=S1414-69752004000200008\&lng=pt\&nrm=i so>. Acesso em: 3 jul. 2007.

Recebido: 04/01/2011

Received: 01/04/2011

Aprovado: 25/03/2011

Approved: 03/25/2011 